\title{
Estudio sobre la existencia de lesiones oculares tras el embolado de los toros
}

\author{
Study on the existence of eye injuries after the bulls have been charged
}

Fecha de recepción y aceptación: 19 de febrero de 2021 y 23 de junio de 2021

DOI: https://doi.org/10.46583/nereis_2021.13.818

\section{Carla Ibáñez Sanchis ${ }^{1 *}$, Javier Mazón Marín ${ }^{1}$ y Marta López Tarancón ${ }^{1}$}

${ }^{1}$ Departamento de Producción Animal y Salud Pública. Facultad de Veterinaria y Ciencias Experimentales. Universidad Católica de Valencia San Vicente Mártir.

* Correspondencia: Universidad Católica de Valencia San Vicente Mártir. Facultad de Veterinaria y Ciencias Experimentales. Departamento de Producción Animal y Salud Pública. Calle Guillem de Castro, 94. 46003 Valencia. España.E-mail: carla.ibanez@ucv.es

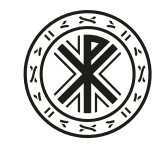

Universidad Católica de Valencia San Vicente Mártir

\section{RESUMEN}

El presente trabajo está enfocado, por un lado, al conocimiento sobre el toro embolado y, por otro lado, al estudio del globo ocular en esta especie. Mediante la unión de estos dos conceptos se pretende realizar una investigación sobre la existencia de lesiones oculares a causa del embolado en estos animales durante festejos populares. Las muestras se obtienen de 26 toros de lidia que han sido embolados a lo largo de varias temporadas con una media de 9 emboladas en cada animal. Un total de 52 ojos, que han sido objeto de este estudio, se obtuvieron acto seguido de su sacrificio en un matadero. Posteriormente, se realizó en primer lugar un examen macroscópico, concretamente, el examen externo del globo ocular, y a continuación, el test de fluoresceína, la evaluación ecográfica y del fondo del ojo. En segundo lugar, se llevó a cabo un examen microscópico observando la retina a partir de cortes histológicos. Los resultados de las pruebas desprenden que el 9,6 \% de los ojos estudiados presentaron lesiones, las cuales se asocian principalmente a problemas de manejo.

PALABRAS CLAVE: toro de lidia, toro embolado, ojo, lesiones.

\section{ABSTRACT}

The present project is mainly focused, on the one hand, on the study of bull-on-fire and, on the other hand, on the study of the eyeball in these species. In order to accomplish this study, a research on the eye damages caused by the "embolado" in these animals during popular festivities were conducted. Twenty six fighting bulls, which have suffered from this kind of activity over several years with an average of nine "emboladas" in each animal, have been taken as a sample in order to carry out this project. A total of 52 eyes were obtained immediately after being sacrificed in a slaughterhouse. Subsequently, a macroscopical examination was accomplished, in particular, the external examination of the eyeball, the fluorescein test, the ultrasound and fundus assessment. After that, a microscopic examination was carried out analyzing the retina from histological sections. The results of the tests show that $9.6 \%$ of the studied eyes were damaged, which were mainly associated with handling problems.

KEYWORDS: fighting bull, bull-on-fire, eye, injuries. 


\section{INTRODUCCIÓN}

\section{Toro de lidia}

$\mathrm{Al}$ hacer referencia a las producciones que ofrece la especie bovina, el pensamiento nos conduce hacia la carne o la leche, sin embargo, existen otras en las cuales se contempla el comportamiento y, dentro de este, se sitúa la bravura [1].

Con respecto al origen del toro de lidia existen varias teorías y todas ellas presentan un punto coincidente en Mesopotamia; el Uro (Bos taurus primigenius). Desde allí realiza varias migraciones: a través de los Cárpatos, al norte, hacia Europa, y por el sur hacia el norte de África, hasta llegar finalmente a España por dos vías: por los Pirineos en el norte y por el estrecho de Gibraltar en el sur [2]. En la actualidad, la raza bovina de lidia es clasificada como autóctona de fomento [3]. Se ha criado y seleccionado desde hace más de tres siglos con el principal objetivo de la lidia en espectáculos taurinos $[3,4]$.

\section{Ganadería de lidia autóctona de la Comunidad Valenciana}

De la misma forma que la ganadería de lidia se desarrolla a lo largo de toda la península ibérica, también presenta una evolución similar en la Comunidad Valenciana. Aunque antiguamente los animales pastaban en los marjales, barrancos y riberas de ríos, hoy en día no son ganaderías ligadas al suelo; han pasado a ser un tipo de explotación intensiva debido a que a los animales se les debe proporcionar el alimento casi en su totalidad por las pequeñas dimensiones que poseen las fincas en esta región. Consecuentemente, se ha desarrollado un sistema de explotación propio basado en el aporte del alimento [5], el cual, entre otras peculiaridades, aprovecha los subproductos hortofrutícolas generados por la industria agroalimentaria de la zona.

\section{Festejos populares}

Se conoce como "bous al carrer", que traducido al castellano sería toros en la calle, a los festejos populares que se realizan en los pueblos valencianos. Entre las diferentes variantes existentes, el toro embolado es uno de los más numerosos, siendo mayoritarios en la provincia de Castellón.

\section{Anatomía}

El ojo, órgano de la visión, se sitúa en el interior de la órbita, y a su vez dentro del cráneo. Se encuentra protegido externamente por los anejos oculares: los párpados y las pestañas. Se considera un órgano complejo que puede verse como una extensión del cerebro. "Captura" imágenes del ambiente a través de un sistema óptico compuesto por lentes y medios de refracción, proyectando así la imagen sobre la capa de células fotosensibles en la retina [6]. 


\section{Órbita ocular}

La órbita es la fosa ósea que separa el ojo de la cavidad craneal, lo rodea y protege, y proporciona varias vías a través de agujeros para los diversos vasos sanguíneos y nervios involucrados en su función. Por otro lado, en concreto, los bovinos, poseen una órbita cerrada, cuyo diámetro es de $65 \mathrm{~mm}$, lo que se ha teorizado como esencial para la protección y refuerzo del cráneo en los ritos de dominancia intraespecie [7].

En particular, en los rumiantes, las órbitas se posicionan más lateralmente que en los carnívoros, aproximadamente a $50^{\circ}$ de la línea media (figura 1). Esta posición permite que la visión monocular en esta y otras especies de ungulados se vea mejorada, por lo que proporciona una amplia visión panorámica que sirve para identificar potenciales depredadores de una forma eficaz.

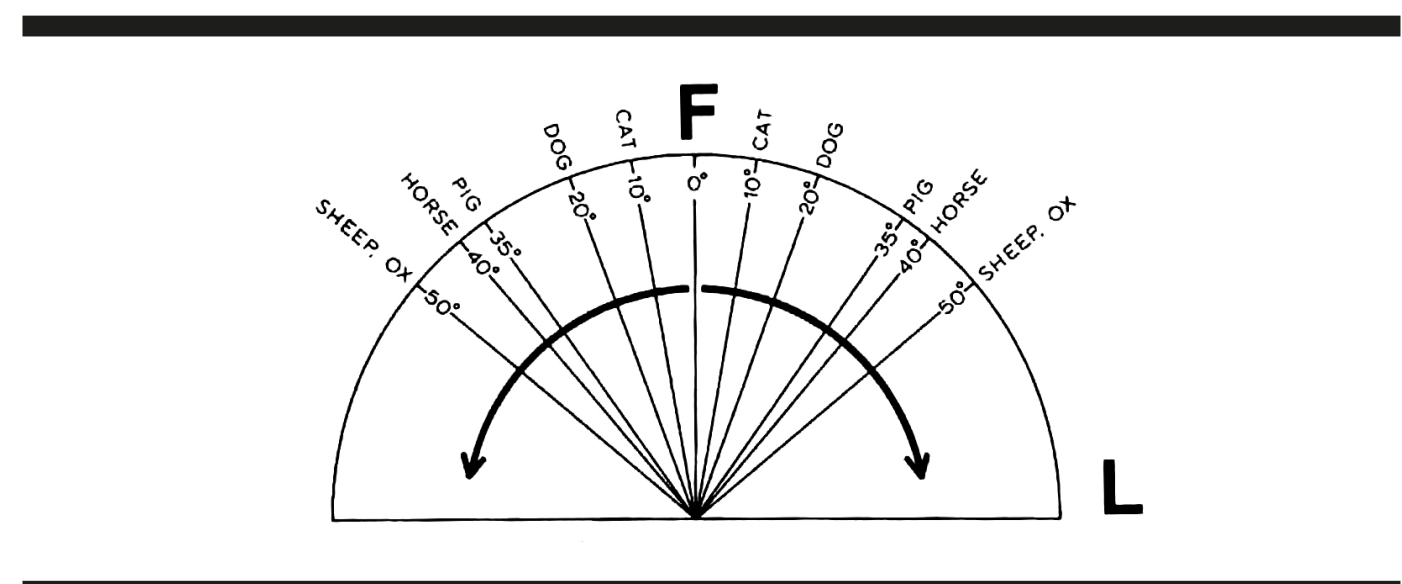

Fig. 1. Comparación de los ángulos formados por los ejes ópticos de diferentes especies domésticas. F, frontal; L, lateral. Fuente: Gelatt. Veterinary ophthalmology.

\section{Músculos extraoculares (MEO)}

Los MEO suspenden el globo en la órbita y le proporcionan movilidad. Existen cuatro músculos rectos (dorsal, ventral, medial y lateral), dos músculos oblicuos (dorsal y ventral), el músculo retractor del globo del ojo y el músculo elevador del párpado superior [7, 8].

\section{Globo ocular}

El globo ocular está compuesto por tres capas o túnicas: fibrosa, intermedia o úvea y nerviosa.

La capa más externa o túnica fibrosa, da forma y protege al globo ocular. Está compuesta de dos partes: córnea y esclerótica. La córnea, con origen embrionario en el ectodermo superficial, se sitúa en la parte anterior ocupando el $10 \%$ de su superficie. Su principal función es la transmisión y refracción de luz gracias a su transparencia, al tiempo que supone un soporte del contenido intraocular. En concreto, en los bovinos, se trata de una estructura más rígida y prominente que en otras especies 
como el ser humano [9]. Además, presenta una forma elíptica, siendo el eje horizontal (27-32 mm) mayor que el vertical (22-24 mm) [9]. La zona de transición entre la córnea y la esclerótica se denomina limbo.

La esclerótica, originada en el mesodermo embrionario, de color blanco, supone el $90 \%$ de la túnica fibrosa, siendo su principal función la de sostén del globo ocular. Se corresponde con el lugar de anclaje de los músculos oculares y su función básicamente es la protección de las estructuras internas $[7,8,9]$.

El espacio existente entre la córnea y el iris se denomina cámara anterior, mientras que el que se sitúa entre el iris y cristalino se denomina cámara posterior. Ambos contienen humor acuoso y se encuentran comunicados a través de la pupila. Una de las principales funciones del humor acuoso es nutrir a la córnea y al cristalino. La relación de producción y drenaje de este establece la presión intraocular, cuyo valor en el bovino oscila entre 20 y $30 \mathrm{mmHg}$ [9]. También debemos destacar el ángulo iridocorneal, cuya función es el drenaje del humor acuoso.

La capa intermedia o úvea se divide en coroides, cuerpo ciliar e iris. A diferencia de la túnica fibrosa, esta capa está muy vascularizada y, normalmente, pigmentada. Tanto la coroides como el cuerpo ciliar están adheridos a la superficie interna de la esclerótica [7]. También se puede dividir la úvea como anterior y posterior. Siendo el iris y el cuerpo ciliar quienes forman la parte anterior y la coroides la posterior [7].

La coroides, al igual que la esclerótica, está formada a partir del mesodermo, y se sitúa entre la retina y la esclerótica, compuesta principalmente por vasos sanguíneos y tejido de soporte pigmentado. Se considera la mayor fuente nutritiva de las capas más externas de la retina. Además de las diversas capas vasculares, está constituida por una capa no vascular que refleja la luz, denominada tapete lúcido (tapetum lucidum) [7, 8].

El cuerpo ciliar, formado a partir del neuroectodermo, es la continuación de la coroides, con forma de anillo que se une al iris. Sus funciones se basan en el aporte nutritivo y eliminación de los desechos de estructuras oculares como la córnea y el cristalino. Por otro lado, desde el cuerpo ciliar se emiten unas prolongaciones conocidas como procesos ciliares, que se unen al borde ecuatorial del cristalino suspendiendo este entre el cuerpo vítreo y la cámara posterior, al tiempo que son el lugar donde se produce el humor acuoso que rellenará la cámara anterior y posterior del ojo [7, 8, 10].

El iris, que deriva del neuroectodermo, está situado por detrás de la córnea, siendo la continuación del cuerpo ciliar con un espesor de 20 a $80 \mu \mathrm{m}$ [9]. En esta especie, se encuentra muy pigmentado de manera uniforme, lo que proporciona generalmente un color marrón oscuro. Además, encontramos la granula iridica, que está compuesta por unos gránulos muy vascularizados, formados por epitelio pigmentado [11], cuya función es la secreción de humor acuoso [6]. Funciona como un diafragma, para controlar la cantidad de luz que va a penetrar al segmento posterior, por movimientos de midriasis o de miosis, siendo la pupila la abertura resultante que queda en la parte central (figura 2) $[7,8]$. 




Fig. 2. Anatomía de la superficie externa del ojo bovino. A, canto medial del ojo; B, canto lateral del ojo; C, pupila; D, iris. Fuente: elaboración propia.

El cristalino, localizado entre el iris y el cuerpo vítreo, es originado a partir del ectodermo superficial. Se trata de una estructura biconvexa, avascular y transparente con un diámetro en la especie bovina de $19,5 \mathrm{~mm}$ [7]. Su principal función es enfocar la luz en la retina para obtener una imagen clara y nítida.

Entre el cristalino y la retina se encuentra un espacio ocupado por un líquido gelatinoso y transparente denominado cuerpo vítreo. Está formado por agua (humor vítreo) y por fibrillas transparentes (estroma vítreo), constituyendo 2/3 del volumen total del globo ocular (figuras 3 y 4) [7, 8, 9].

Por último, se encuentra la túnica nerviosa, formada por la retina y el nervio óptico. Tanto la retina como el nervio óptico derivan de la parte anterior del cerebro (neuroectodermo), por lo que su morfología y fisiología son similares a él. La retina se encarga de recibir los estímulos lumínicos que provienen del exterior y transmitirlos al cerebro, donde se interpretan. Como particularidad del bovino, los vasos sanguíneos que recorren la retina presentan un patrón holangiótico, lo que significa que contienen tres pares de arteria-vena, una en dirección dorsal, otra medial y otra lateral [10].

En la retina se pueden diferenciar dos zonas: la parte óptica, sensible a la luz, donde se sitúan los fotorreceptores (conos y bastones), y la parte ciega no sensible a la luz [7]. En este punto encontramos la ora ciliaris retinae, que se trata de un lugar de transición entre el área fotosensible y la no fotosensible [12].

Los bastones son células fotorreceptoras delgadas, cuya función es más efectiva con baja iluminación (visión escotópica) y son inactivados ante la exposición constante de luz brillante. Por otro lado, los conos proporcionan una mejor visión durante el día (visión fotópica), pero son menos sensibles a la luz, sobre todo cuando los niveles lumínicos son bajos; además, son los responsables de la percepción del color. En los bovinos, predominan los bastones a los conos. Además, en esta especie, se encuentra un mayor número de conos en el centro de la retina que en la periferia [9].

Anatómicamente, la retina se divide en 10 capas: epitelio pigmentado, capa de fotorreceptores, membrana limitante externa, capa nuclear externa, capa plexiforme externa, capa nuclear interna, capa plexiforme interna, capa de células ganglionares, capa de fibras del nervio óptico y membrana 
limitante interna. Es en las capas plexiforme externa e interna donde se realiza la sinapsis que dará lugar a la transmisión de los estímulos a través del nervio óptico y finalmente llegará al cerebro [12].


Fig. 3. Secciones transversales del globo ocular bovino. A, fondo de ojo; B, mitad rostral y fondo de ojo, vistas del interior; C, mitad rostral y fondo de ojo, vistas del interior una vez eliminados el cristalino, el cuerpo vítreo y la retina. 1, esclerótica; 2, coroides; 3 , tapete lúcido; 4, retina óptica; 5 , cristalino; 6 , cuerpo vítreo; 7, disco óptico;

8 , abertura de la pupila; 9 , iris; 10 , cuerpo ciliar (con los procesos ciliares); 11, ora ciliaris retinae. Fuente: Rojo Salvador. Anatomía del ojo en las especies domésticas.

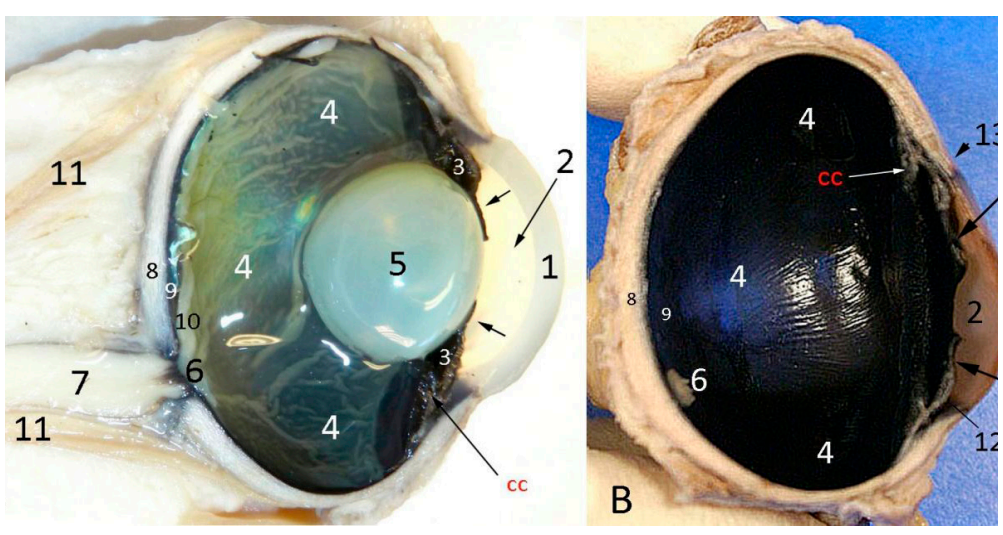

Fig. 4. Cortes sagitales del globo ocular de un bovino (A y B). B, eliminación de cristalino, cuerpo vítreo y retina. Flechas, iris; 1, córnea; 2, cámara anterior; 3, cámara posterior; CC, cuerpo ciliar y procesos ciliares; 4, cámara vítrea (en la Figura A contiene el cuerpo vítreo); 5 , cristalino; 6 , disco óptico; 7, nervio óptico; 8, esclerótica; 9 , coroides; 10 , retina óptica; 11, fibras del músculo retractor del globo del ocular; 12, ángulo iridocorneal; 13, limbo. Fuente: Rojo Salvador. Anatomía del ojo en las especies domésticas. 


\section{Visión del toro}

En lo que respecta al campo de visión, proporciona información sobre el área en la que el animal puede ver sin girar la cabeza, es decir, las imágenes que es capaz de captar con un solo ojo, visión monocular, y con ambos ojos, visión binocular.

Como ya se ha referenciado anteriormente, la posición de los ojos en la cabeza del animal supone una característica muy importante, ya que va a influir notablemente en su visión. En el caso de los bovinos, concretamente en la raza de lidia, al presentar las órbitas lateralmente, cuentan con un campo visual de $292^{\circ}$ en total [9].

Debe señalarse que cuando se habla del plano de visión horizontal debemos hacer referencia, por un lado, al campo monocular, el cual gracias a la posición de las órbitas y a la forma alargada de la pupila se obtiene una visión más extensa en dirección horizontal que en vertical. Además, este campo ofrece una excelente visión de objetos a distancia. En el caso del toro de lidia, su ángulo es de $135^{\circ}$ de media. Por otro lado, se debe hacer referencia al campo binocular, que es el encargado de analizar la zona frontal para ver en profundidad y determinar tanto las distancias a los objetos cercanos como la velocidad del movimiento de estos. Su ángulo, en el ganado bravo, es de $30^{\circ}$. Sin embargo, presentan dos zonas ciegas donde el animal carece de visión, una frontal, también conocida como zona de exclusión, de $30^{\circ}$, la cual va aumentando con la edad, y otra posterior de $68^{\circ}$. Por último, el plano vertical del campo de visión, en el bovino de lidia, cuenta con una angulación de $60^{\circ}$ (figura 5) [9].



Fig. 5. Campos de visión del toro de lidia, siendo * la zona de exclusión. Fuente: elaboración propia.

Cuando se habla de la visión, es importante destacar el proceso de acomodación, el cual hace referencia al cambio del poder de refracción del ojo. Gracias a la contracción del músculo ciliar se consigue enfocar imágenes de objetos cercanos [13].

En ungulados, se presenta una débil acomodación, ya que los músculos ciliares presentan un desarrollo incompleto, teniendo así poca visión de cerca. Como consecuencia, detectan mejor los objetos más cercanos utilizando el sentido del olfato y el oído [13].

Haciendo referencia a la visión en color de los bovinos, anteriormente se ha señalado que los conos son los responsables de percibir los colores. En estos animales se encuentran dos tipos de conos $(\mathrm{S}$ y $\mathrm{M} / \mathrm{L})$ sensibles a diferentes longitudes de onda, lo que resulta en una visión dicromática. 
Concretamente, en el vacuno, la longitud de onda de los conos tipo S es de $451 \mathrm{~nm}$ y para el tipo M/L es de 555 nm (figura 6) $[6,7,14]$.

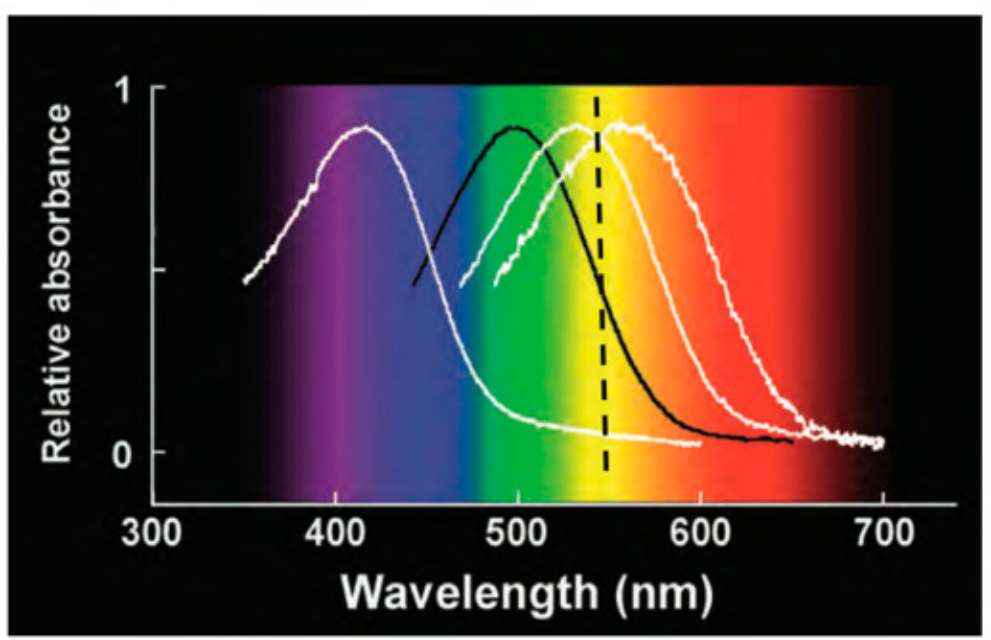

Fig. 6. Espectros de absorción. Curva negra: rodopsina. Curvas blancas:

$\mathrm{S}, \mathrm{M}$ y L, respectivamente. La línea discontinua señala un color aleatorio

"verde-rojo". Fuente: Gelatt. Veterinary ophtalmology.

\section{HISTOLOGÍA}

La histología es la ciencia que estudia la estructura y composición de los tejidos a nivel microscópico. Si se examina el ojo desde la capa más externa a la capa más interna, en primer lugar, aparece la esclerótica, formada por tejido conjuntivo denso con haces paralelos de fibras de colágeno tipo I. La siguiente capa que se visualiza es la coroides, compuesta por tejido conjuntivo laxo muy vascularizado que contiene melanocitos [15]. A continuación, como se ha señalado anteriormente, la retina es la capa más interna del globo ocular, está delimitada externamente por la coroides e internamente por el humor vítreo y presenta diez capas, que de exterior a interior son (figura 7 y 8) $[12,16]$ :

1. Epitelio pigmentado: epitelio cúbico de células poliédricas cargadas de melanina muy relacionadas con los conos y bastones.

2. Capa de fotorreceptores (conos y bastones): constituida por dendritas modificadas que actúan como fotorreceptores (primera neurona). Los núcleos de las células de los conos se disponen en una sola altura y cerca de la membrana limitante.

3. Membrana limitante externa: se encuentra relacionada con las uniones de las prolongaciones externas de las células de Müller, que son células gliales, también, con los conos y bastones.

4. Capa nuclear externa: contiene los cuerpos celulares de los conos y bastones.

5. Capa plexiforme externa: formada por terminaciones axonales de la capa de fotorreceptores haciendo sinapsis con las dendritas de las células bipolares. 
6. Capa nuclear interna: localizada en el punto que comienza la retina y donde termina el humor vítreo. Formada por los cuerpos celulares de las células bipolares (segunda neurona).

7. Capa plexiforme interna: donde tiene lugar la sinapsis entre las células bipolares y las células ganglionares.

8. Capa de células ganglionares (tercera neurona): células que van a componer el nervio óptico. Presentan un núcleo grande y claro con el citoplasma repleto de ARN.

9. Capa de fibras del nervio óptico: constituida por los axones de las células ganglionares. Estos van a salir por la lámina cribosa de la esclerótica formando así el nervio óptico.

10. Membrana limitante interna: se trata de una capa continua formada por las prolongaciones internas de las células de Müller que forman una lámina basal que la separa del humor vítreo.

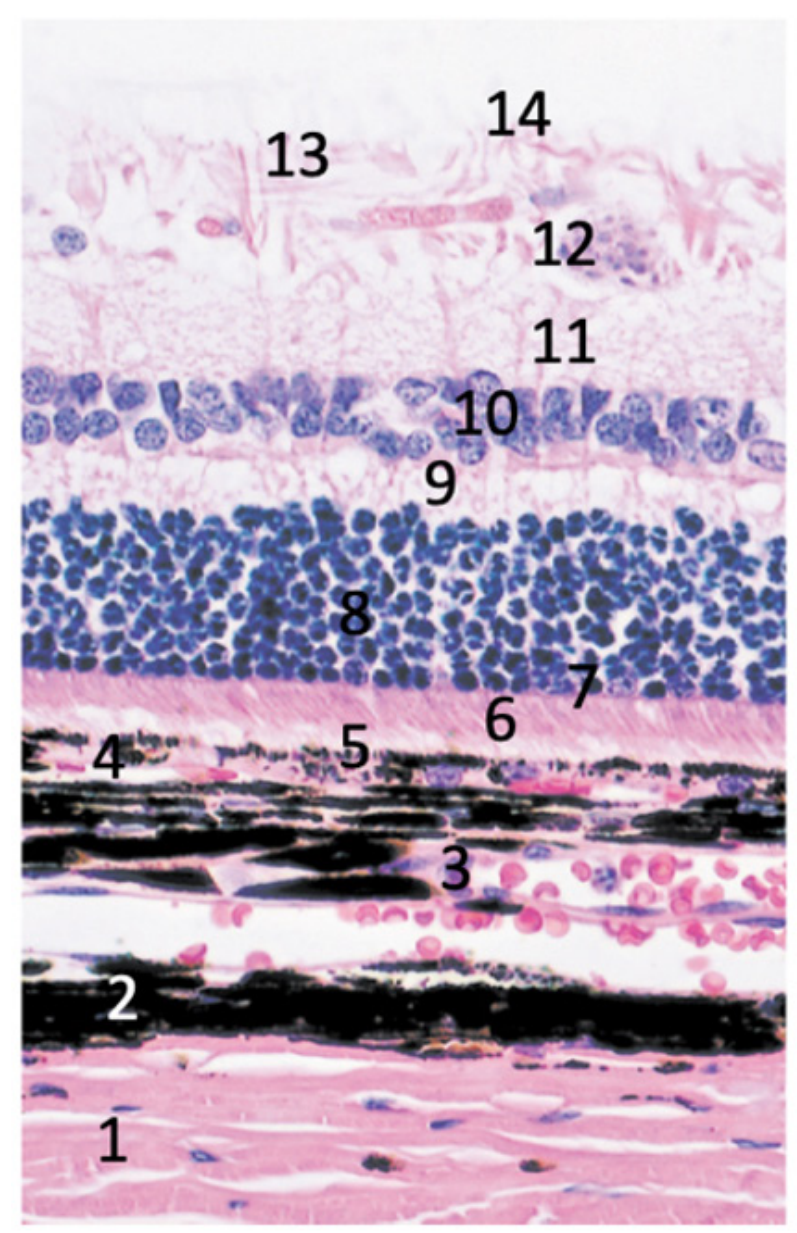

Fig. 7. Histología de retina, coroides y parte de la esclerótica. 1, esclerótica; 2, melanocitos; 3 , coroides; 4 , capa coriocapilar; 5 , epitelio pigmentado; 6 , capa de fotorreceptores; 7 , membrana limitante externa; 8 , capa nuclear externa; 9 , capa plexiforme externa; 10 , capa nuclear interna;

11, capa plexiforme interna; 12, capa de células ganglionares; 13, capa de fibras nerviosas; 14, membrana limitante interna. Fuente: Bacha. Color atlas of veterinary histology. 
Con respecto al cristalino, se pueden diferenciar tres partes: las fibras del cristalino, la cápsula del cristalino y el epitelio subcapsular. Las fibras del cristalino se presentan en forma de elementos prismáticos finos y largos. Pierden sus núcleos y se alargan de manera considerable. En cuanto a la cápsula del cristalino, esta presenta un revestimiento acelular homogéneo hialino, con una estructura muy elástica constituida mayormente por colágeno tipo IV y glucoproteínas. Finalmente, el epitelio subcapsular está formado por una capa de células epiteliales cúbicas que se encuentran solamente en la parte anterior del cristalino (figura 8) [16].

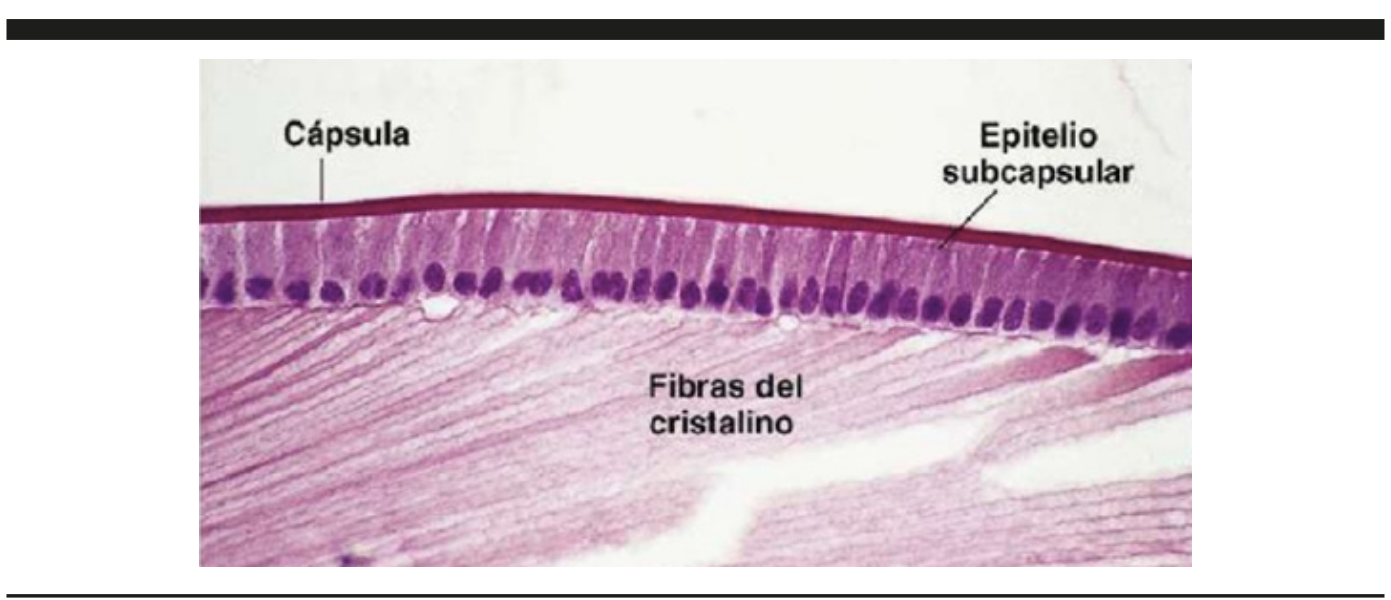

Fig. 8. Corte histológico del cristalino. Fuente: Junqueira. Histología básica.

En la histología del iris se puede diferenciar, por un lado, la capa epitelial externa, formada por células planas, y, por otro lado, la capa epitelial interna, que contiene una doble capa de células pigmentadas. En esta estructura se localiza un músculo dilatador y otro constrictor, cuya función es regular el diámetro de la pupila (figura 9) [16].

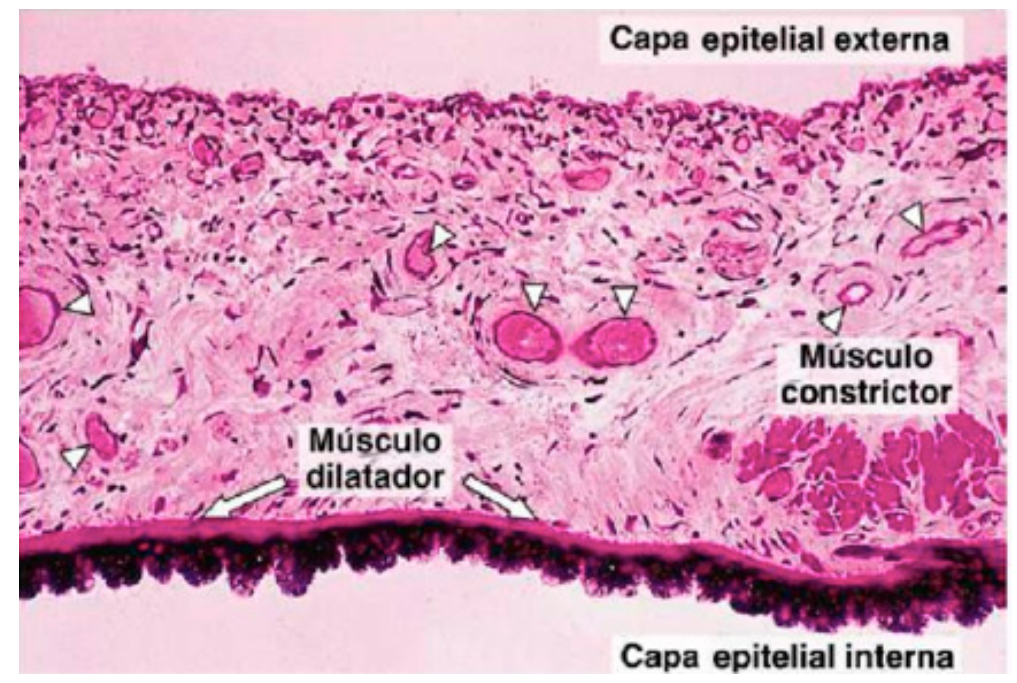

Fig. 9. Corte histológico del iris. Fuente: Junqueira. Histología básica. 
Anterior al iris se encuentra la córnea. Esta se puede dividir en cinco capas: el epitelio anterior, formado por el epitelio estratificado plano no queratinizado, la membrana de Bowman, que contribuye a reforzar la estructura de la córnea, el estroma, que contiene numerosas capas de fibras de colágeno, la membrana de Descemet, cuyas fibrillas colágenas están organizadas como una red tridimensional y, por último, el epitelio posterior o endotelio, que es un epitelio plano o cúbico simple (figura 10) [16].

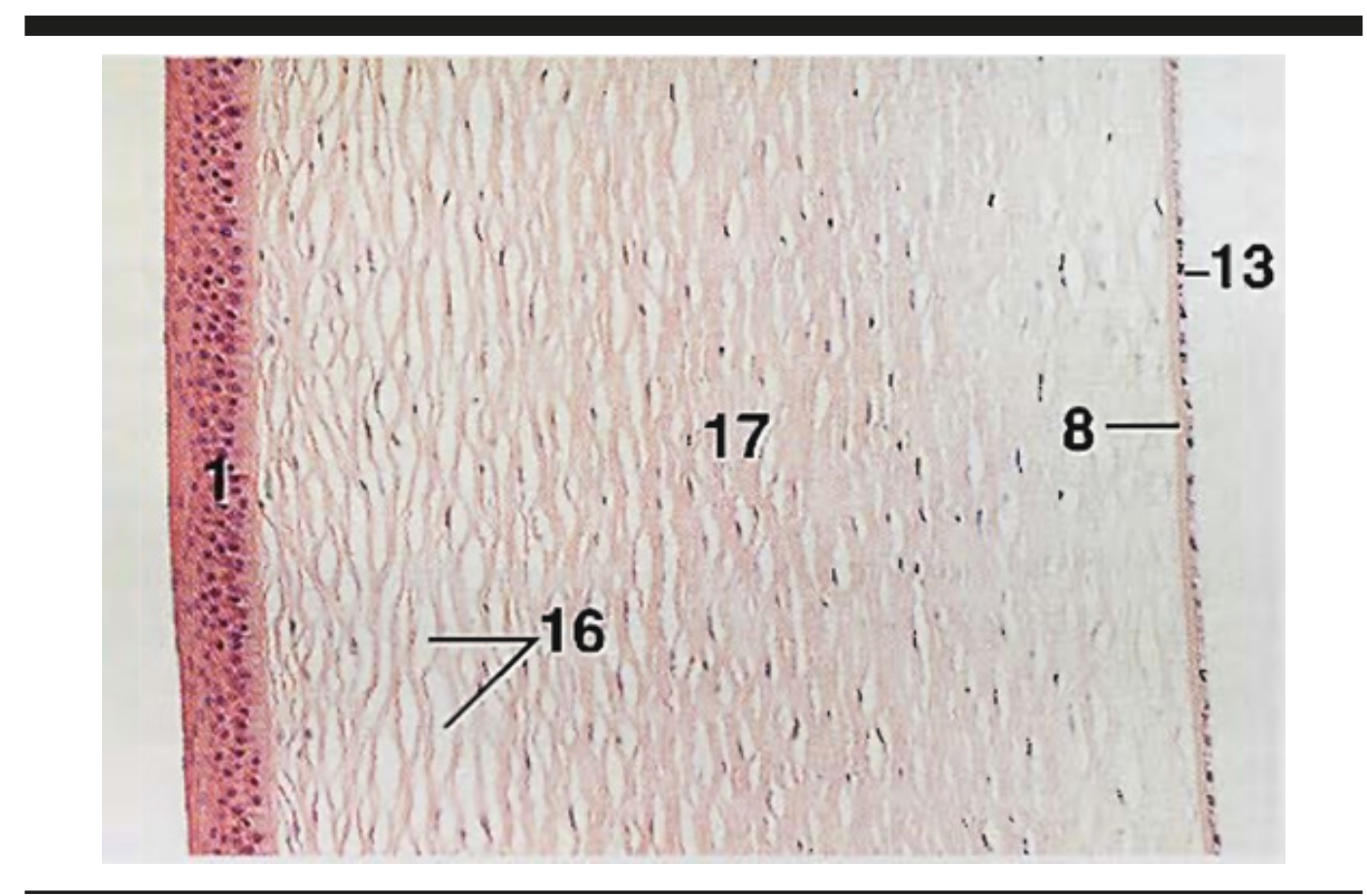

Fig. 10. Corte histológico de la córnea. 1, epitelio anterior; 8, membrana de Descemet; 13, epitelio posterior; 16, espacio (artefacto); 17, estroma. Fuente: Bacha. Color atlas of veterinary histology.

\section{Fundamentos ecográficos}

La ecografía ocular permite evaluar el globo y las estructuras de la órbita, que consisten en los tejidos dentro del cono periorbital en el área retroorbital, incluido el nervio óptico, los músculos extraoculares, los vasos, la grasa, la superficie del hueso orbitario, los tejidos blandos y las glándulas alrededor del globo ocular [17].

Las estructuras del globo ocular del bovino presentan una apariencia ecográfica muy similar a la de otras especies [6]. 


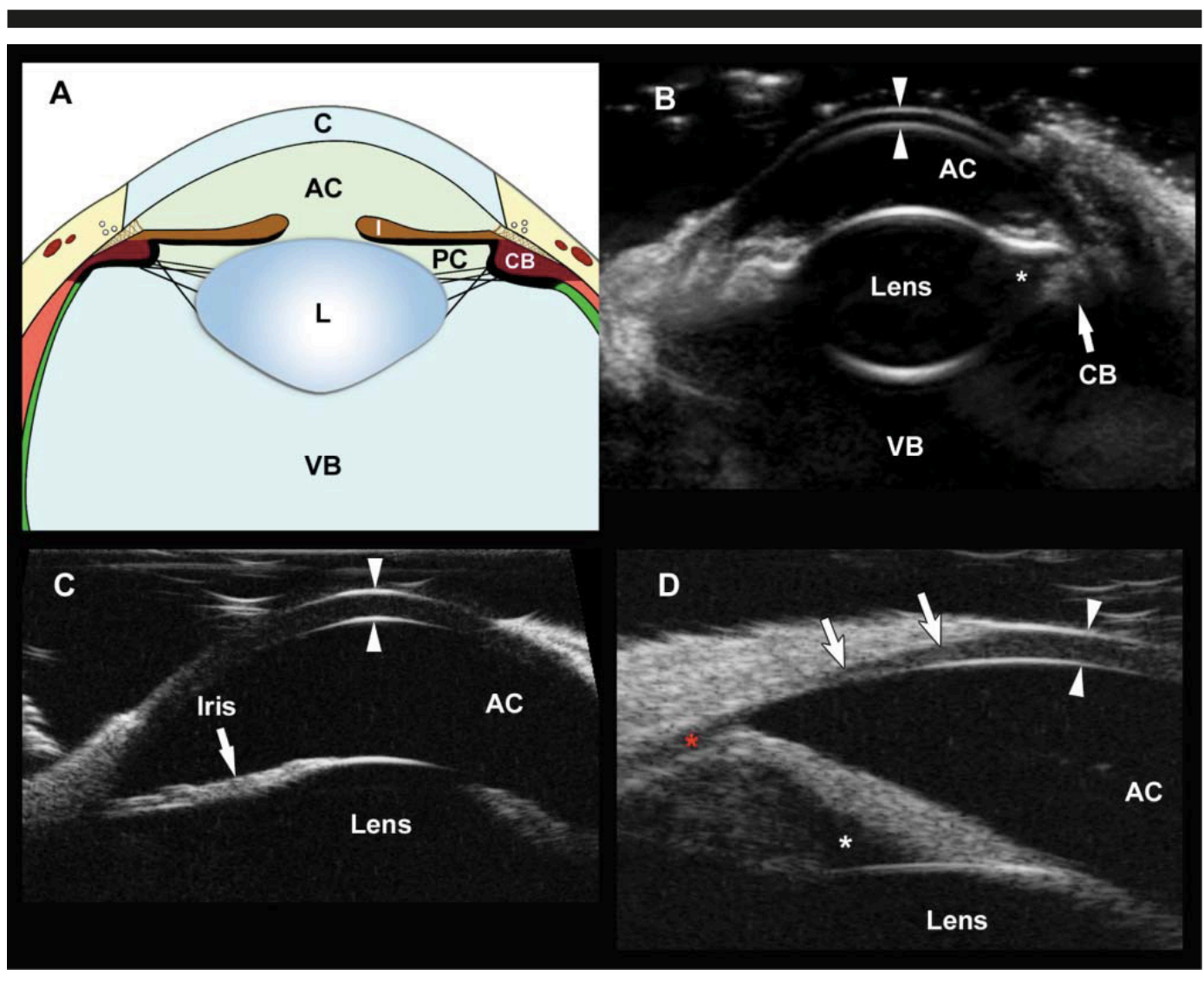

Fig. 11. Segmento anterior del ojo (A). C, córnea; AC, cámara anterior; I, iris; PC, cámara posterior; L, cristalino; VB, cuerpo vítreo; $\mathrm{CB}$, cuerpo ciliar. Ecografía de alta resolución de la córnea, cámaras anterior y posterior (B). CB, cuerpos ciliares; puntas flecha, doble línea ecogénica de la córnea; *, cámara posterior. Fuente: Penninck. Atlas of small animal ultrasonography.

En el ojo normal, la cámara anterior, la cual es difícil de localizar a causa de su compresibilidad y tamaño, la cámara posterior y el cuerpo vítreo se representan como una región anecoica. En función de la frecuencia de la sonda, la córnea se visualiza normalmente como una doble línea hiperecoica paralela, con un espacio central anecoico. Esta se ve distendida con humor acuoso anecoico. Además, su profundidad varía en función de la raza y la edad. La pupila aparece como una zona anecoica en la parte central del iris. La apariencia normal del interior del cristalino es anecoica, aunque la cápsula anterior y posterior se observan hiperecoicas. La pared posterior del globo está formada por una capa delgada, hiperecoica y lisa que representa, de exterior a interior, la combinación de las capas de la esclerótica, la coroides y la retina, las cuales no se diferencian entre sí en el globo ocular normal (figura 11) [17].

El espacio retrobulbar, donde se incluyen los músculos extraoculares, el nervio óptico, las arterias, las venas, y la grasa periorbital, también pueden ser ecografiados. El hueso frontal, el cual forma la pared medial de la órbita, aparece hiperecogénico con sombra. Los músculos extraoculares son estructuras hipoecoicas. El nervio óptico es una estructura delgada, lineal, hipoecoica, que se encuentra delineada por grasa adyacente hiperecoica [17]. 
También se pueden obtener imágenes de la glándula lacrimal, situada en el lado lateral de la órbita, y la glándula salival cigomática, situada ventrocaudal al globo ocular y ventral al cono orbital [17].

La finalidad del presente trabajo es evaluar si se producen lesiones macroscópicas y/o microscópicas en el ojo de los toros embolados después de repetidas emboladas a lo largo de los años. Específicamente, se desea:

1. Determinar la presencia de lesiones en el examen externo.

2. Evaluar los resultados del test de fluoresceína.

3. Evidenciar las posibles lesiones a nivel de la retina manifestadas mediante ecografía.

4. Identificar la aparición de lesiones en el fondo del ojo.

5. Estudiar si existen lesiones a nivel histológico de la retina.

\section{MATERIAL Y MÉTODOS}

Para realizar el presente estudio, un total de 52 ojos procedentes de 26 toros que habían sido embolados fueron obtenidos en un matadero durante el mes de septiembre de 2019. La edad de los animales estaba comprendida entre los 4 y 9 años y la media de emboladas a las que se había sometido a los animales a lo largo de su vida útil era de 9.

La dificultad de obtención de estas muestras radica en lograr los permisos necesarios de un sector muy receloso de todo aquello que puede perjudicarle y que solo el conocimiento personal ha permitido vencer $y$, por otra parte, lograr muestras de animales que han permanecido en las ganaderías durante varias campañas consecutivas siendo embolados en múltiples ocasiones, lo que permite valorar la existencia de posibles lesiones debidas a la repetición de la embolada.

\section{Procedimiento}

La extracción del globo ocular se realizó siguiendo el proceso de enucleación, donde el ojo y su contenido son extirpados junto a los párpados utilizando bisturí y pinzas. La extracción se realizó en el matadero inmediatamente después de finalizar la carnización.

Realizada la enucleación se efectuó un examen macroscópico (examen externo y test de fluoresceína) para detectar posibles lesiones y, a continuación, los ojos se introdujeron en botes con suero salino fisiológico. La metodología para diferenciar el ojo derecho del izquierdo fue dejando en el ojo derecho una mayor cantidad de piel. La nomenclatura de cada muestra se estableció en función del día en que esta se obtenía.

Una vez transportadas las muestras al Hospital Veterinario de la Universidad Católica de Valencia se realizaron pruebas ecográficas y de disección del globo ocular.

\section{Estudio macroscópico}

Se realizó un examen físico externo en busca de anomalías, prestando mayor atención a la córnea. 
El test de fluoresceína no revela ningún resultado sobre la córnea sana, sin embargo, las córneas que presentan algún tipo de alteración evidencian un área teñida de color verde brillante debido a la fijación de la fluoresceína al estroma de la córnea. Se trata de una prueba sencilla que requiere de la ayuda de una lámpara de Wood para realizar su lectura [18].

A fin de clasificar la gravedad de las úlceras en base a su extensión y profundidad en el estroma, se estableció una escala del 1 al 5, asignando el valor 1 a las úlceras menos graves y el 5 a las más graves.

Posteriormente se realizó una ecografía en modo B para visualizar las estructuras internas del ojo. Se utilizó una sonda curva de $10 \mathrm{MHz}$ posicionada tanto en vertical como en horizontal respecto al ojo, con un ecógrafo (marca Vinno E30) propiedad del Hospital Veterinario de la Universidad Católica de Valencia, que realiza un barrido de izquierda a derecha para visualizar las diferentes estructuras oculares.

Por último, se procedió a la disección del ojo con la finalidad de observar su fondo. Para ello, se realizó una incisión circular alrededor de la córnea por la zona del limbo y posteriormente fue retirada. Seguidamente, con la ayuda de unas pinzas, se retiró el iris y después el cristalino utilizando un asa de cristalino. De esta manera se consigue ver el fondo del ojo a través del humor vítreo, siendo habitual la presencia de gránulos de melanina.

\section{Estudio microscópico}

La finalidad de esta parte del estudio fue obtener cortes histológicos de la retina. Para ello, una vez terminado el examen macroscópico se introdujeron todos los ojos en Formaldehído al 4 \% (VWR Chemicals $\left.{ }^{\circledR}\right)$ con el objetivo de evitar la descomposición de los tejidos. Seguidamente se trasladaron al Instituto Valenciano de Patología de la Universidad Católica de Valencia para la realización del examen histológico.

\section{RESULTADOS}

De los 26 animales examinados, que proporcionaron 52 ojos (figura 12), en el examen externo tan solo 4 presentaron alteraciones: 2 muestras presentaron opacidad corneal (figura 13) y otras 2 presentaron cicatrices (figura 14). 




Fig. 12. Muestras sometidas al examen externo. Fuente: elaboración propia.

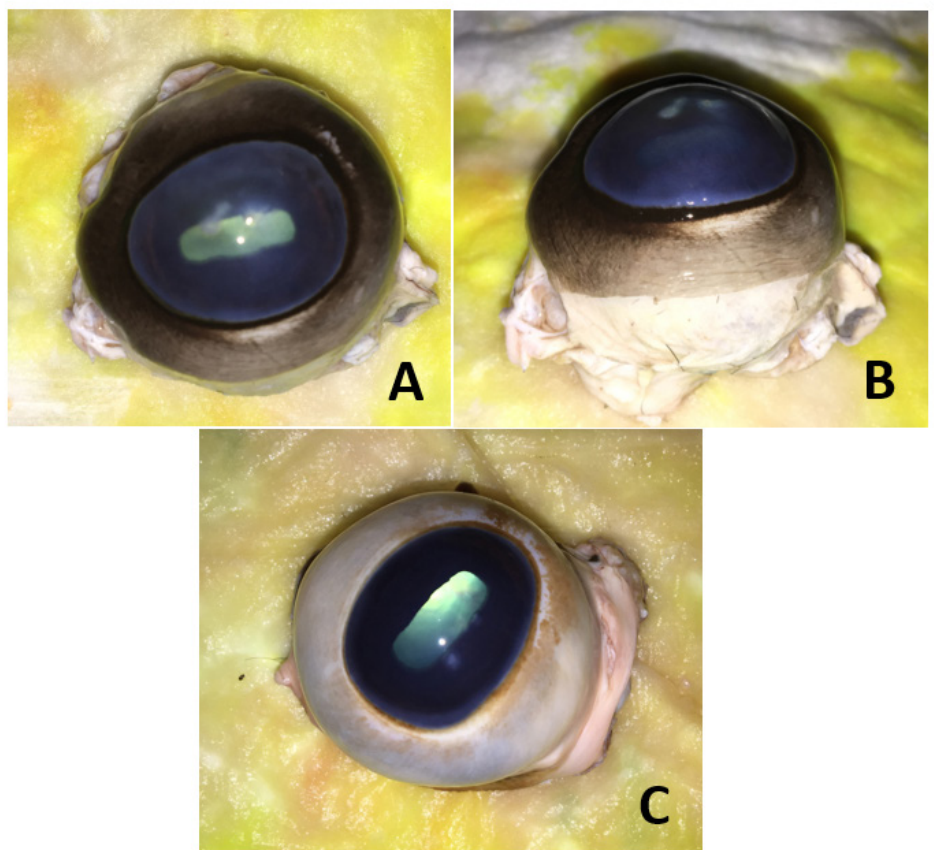

Fig. 13. Presencia de opacidad corneal. A y B, muestra 182, ojo izquierdo; C, muestra 185, ojo izquierdo. Fuente: elaboración propia. 


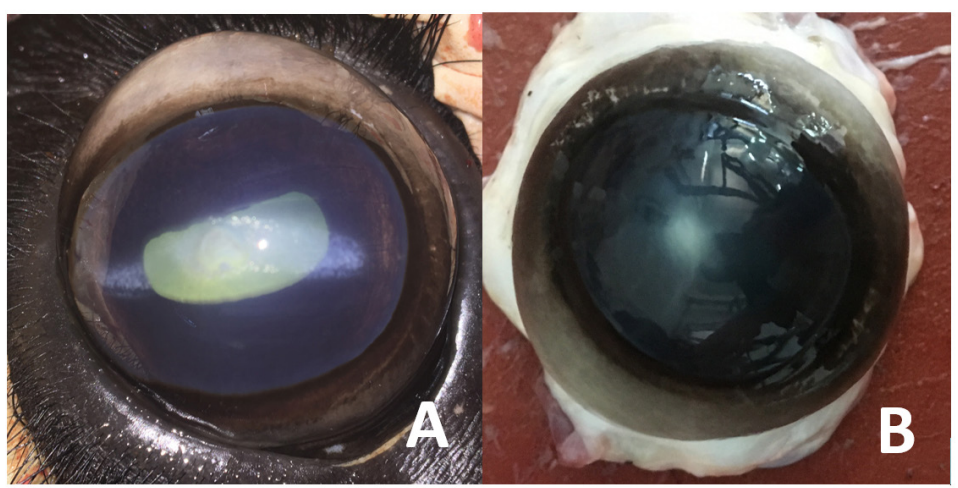

Fig. 14. Cicatrices en la córnea del globo ocular. A, muestra 252, ojo derecho; B, muestra 255, ojo izquierdo. Fuente: elaboración propia.

Realizado el test de fluoresceína a los 52 ojos (figura 15), se hallaron 3 resultados positivos (figura 16). Dos de ellos presentaron previamente alteración al examen externo. En todos los casos las úlceras halladas se clasificaron como tipo 1 .

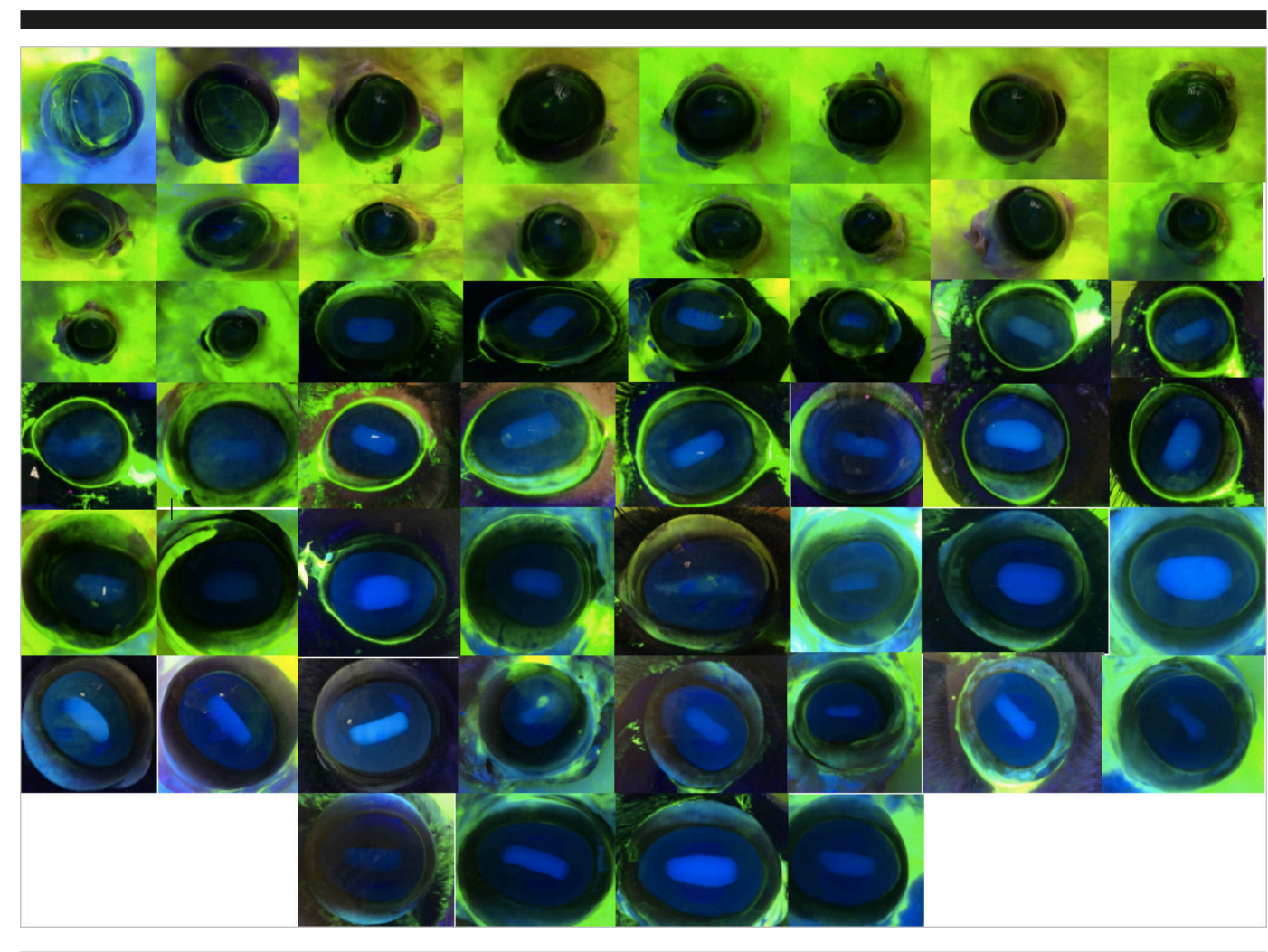

Fig. 15. Muestras sometidas al test de fluoresceína. Fuente: elaboración propia. 


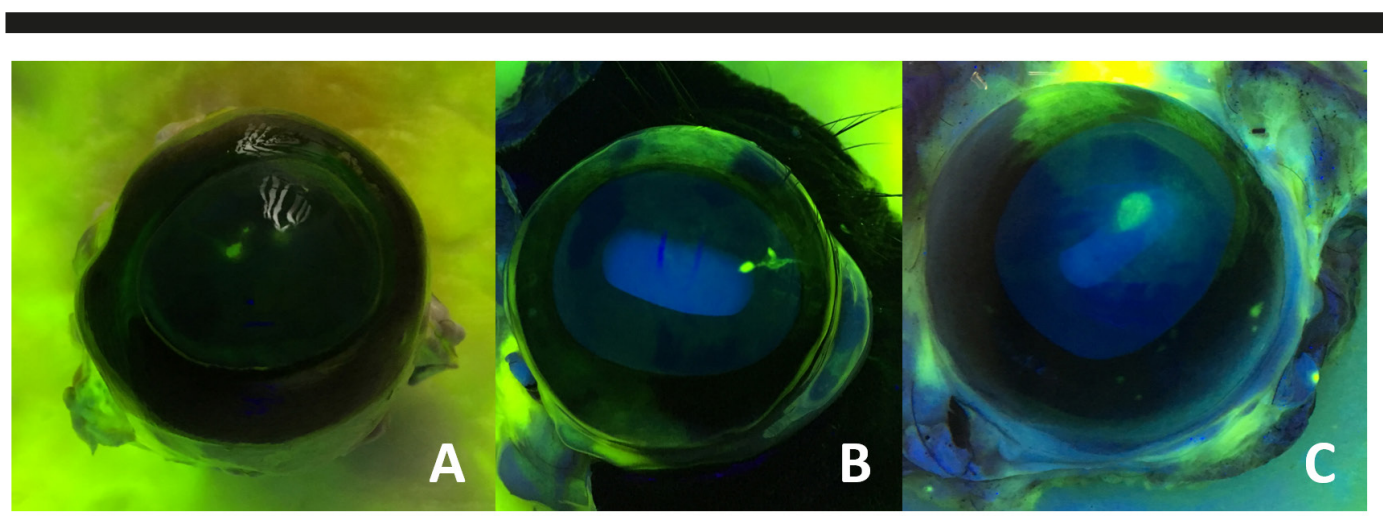

Fig. 16. Reacción positiva a fluoresceína. Úlcera tipo 1. A, muestra 182, ojo izquierdo; B, muestra 192, ojo izquierdo; C, muestra 255, ojo izquierdo. Fuente: elaboración propia.

Posteriormente, se realizó un examen ecográfico de todas las muestras en busca de alteraciones en la parte interna del globo ocular tal y como se ha descrito (figura 17), siendo el resultado negativo en todas ellas (figura 18) (tabla 1).

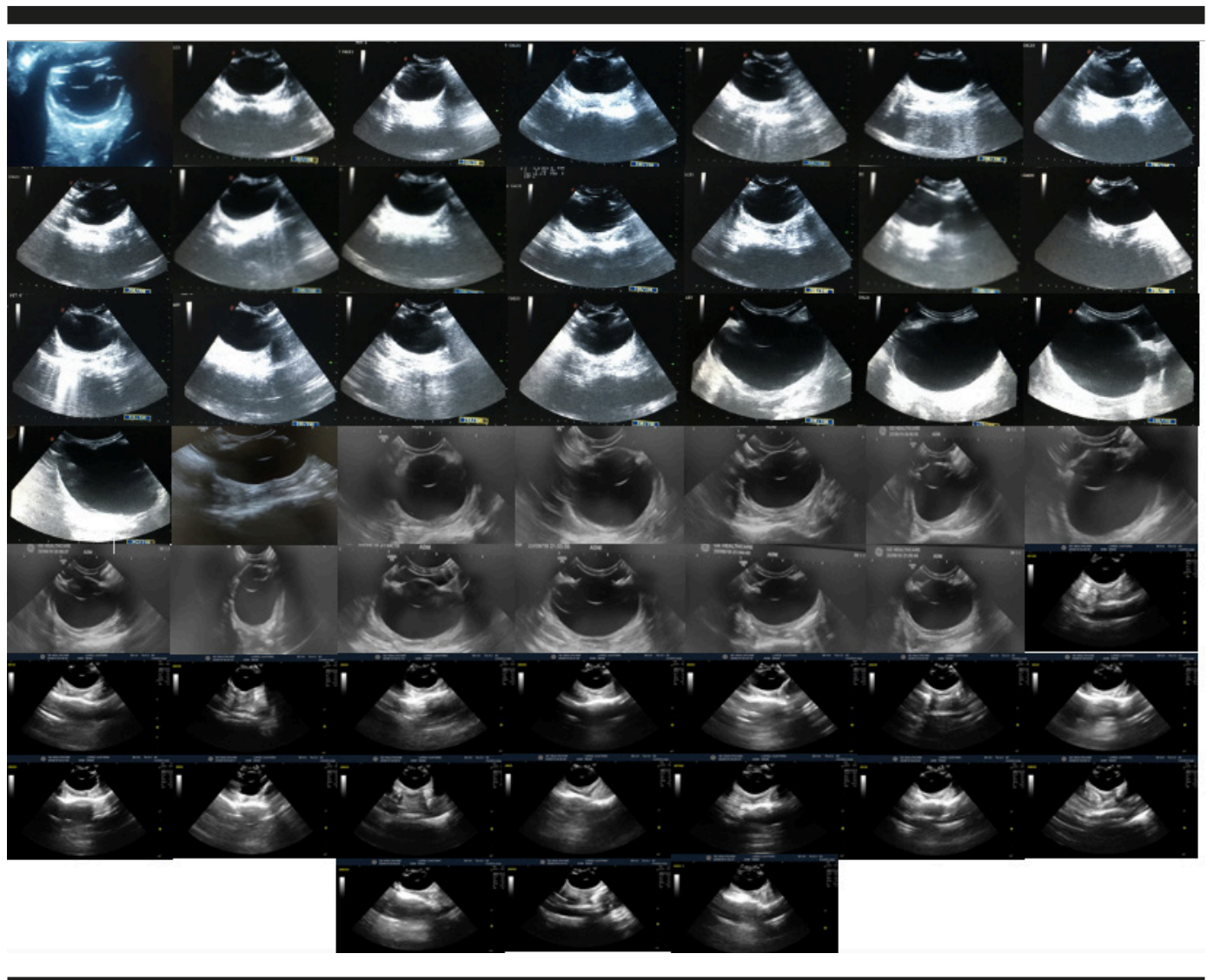

Fig. 17. Muestras sometidas a examen ecográfico. Fuente: elaboración propia. 


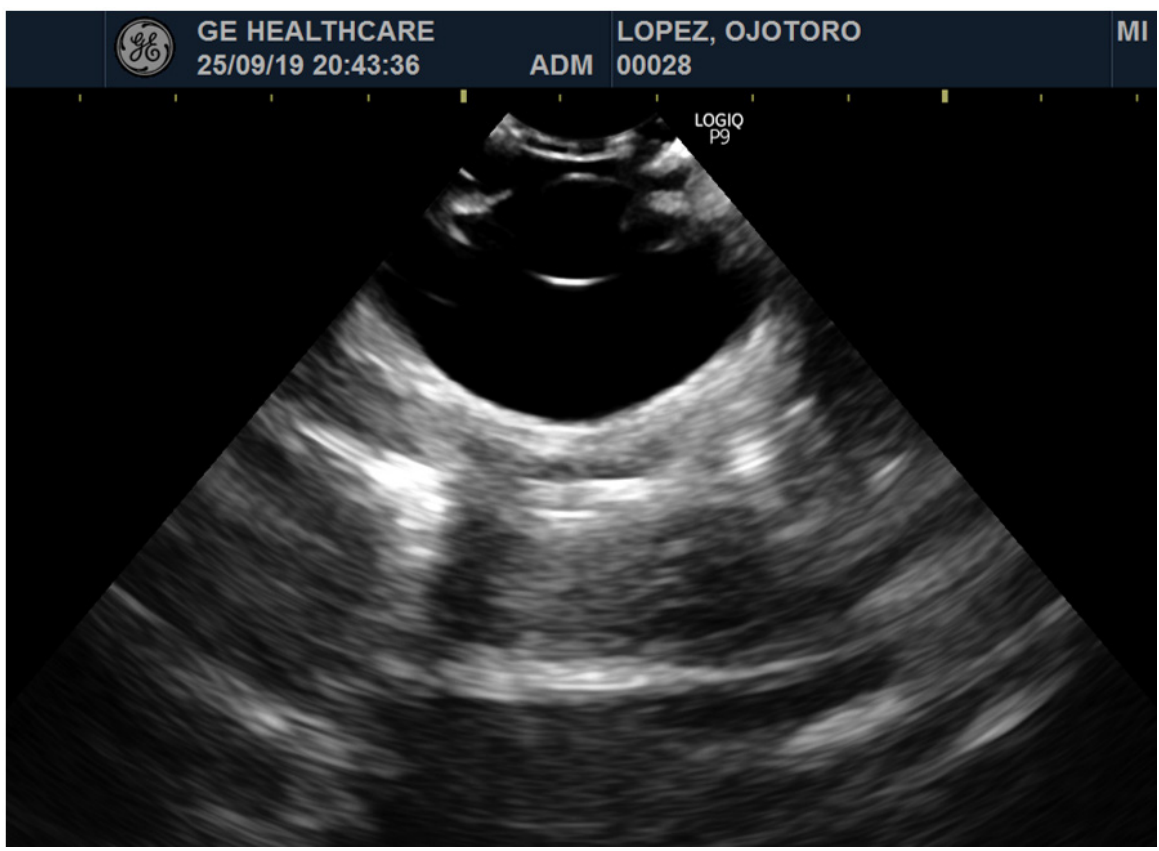

Fig. 18. Ecografía ocular. Fuente: elaboración propia.

En la disección del ojo para poder visualizar su fondo, al igual que en la prueba anterior, de los 52 ojos (figura 19) ninguna muestra reveló alteración alguna (figura 20). Se evidenció la presencia de melanina en 42 animales.

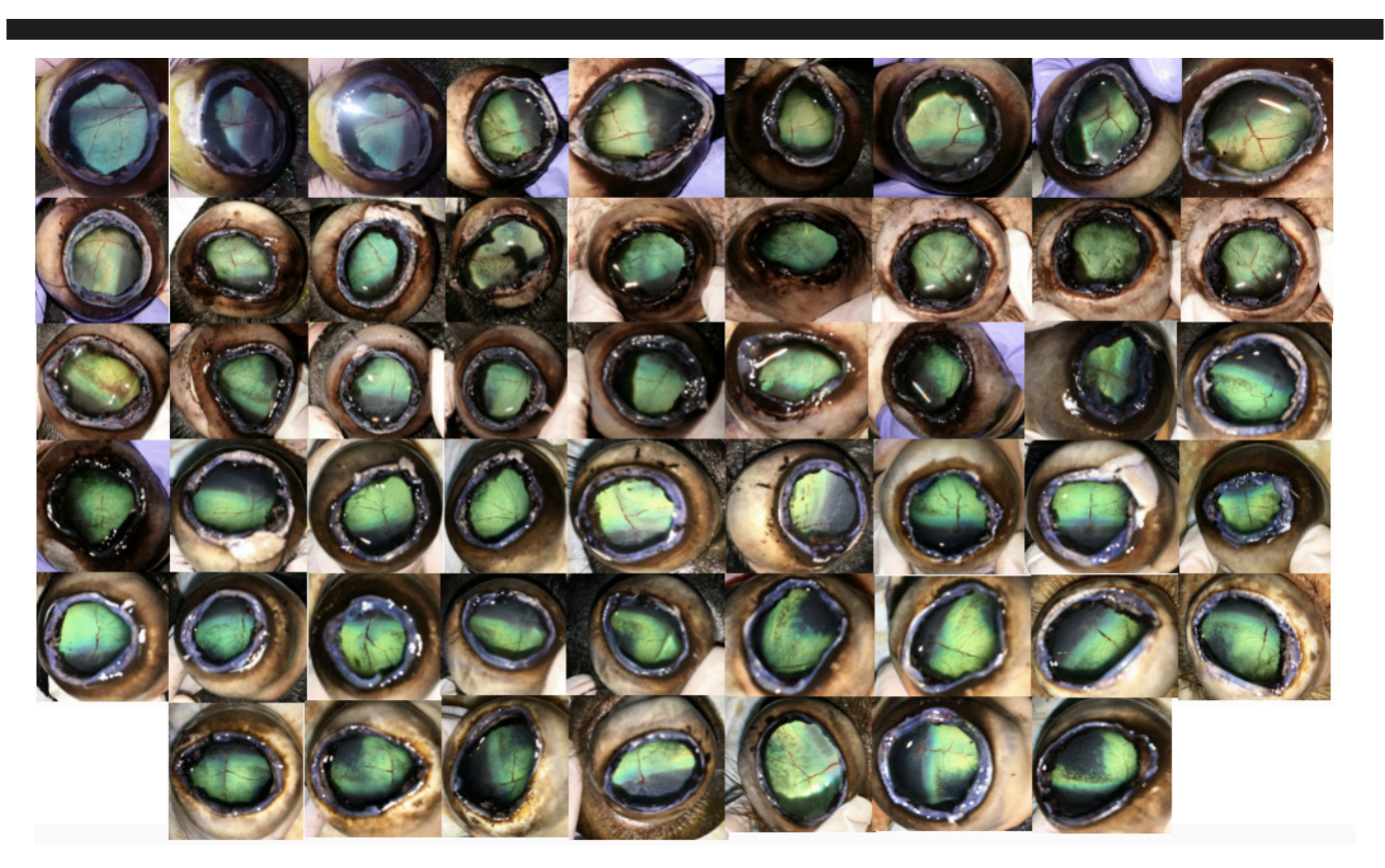

Fig. 19. Muestras sometidas al examen del fondo del ojo. Fuente: elaboración propia. 


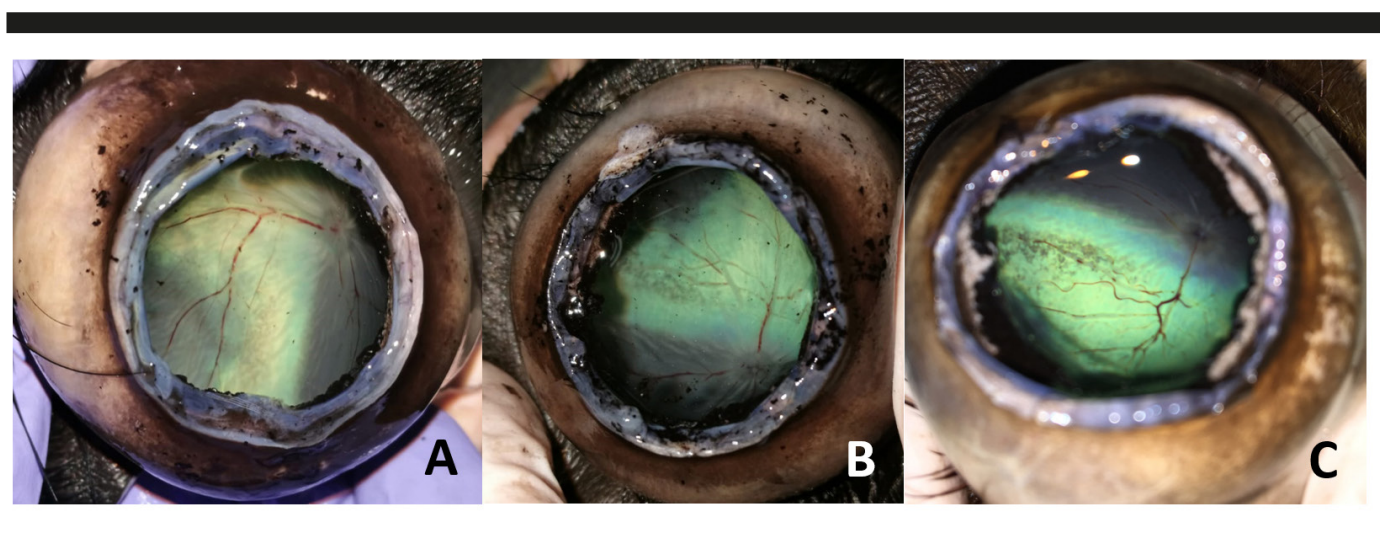

Fig. 20. Fondo del ojo sin ninguna alteración. A, 192, ojo derecho; B, 235, ojo derecho; C, 253, ojo derecho. Fuente: elaboración propia.

Los 52 cortes histológicos estudiados (figura 21), no mostraron ninguna alteración en la retina ni en las estructuras adyacentes (figuras 22 y 23) (tabla 1).

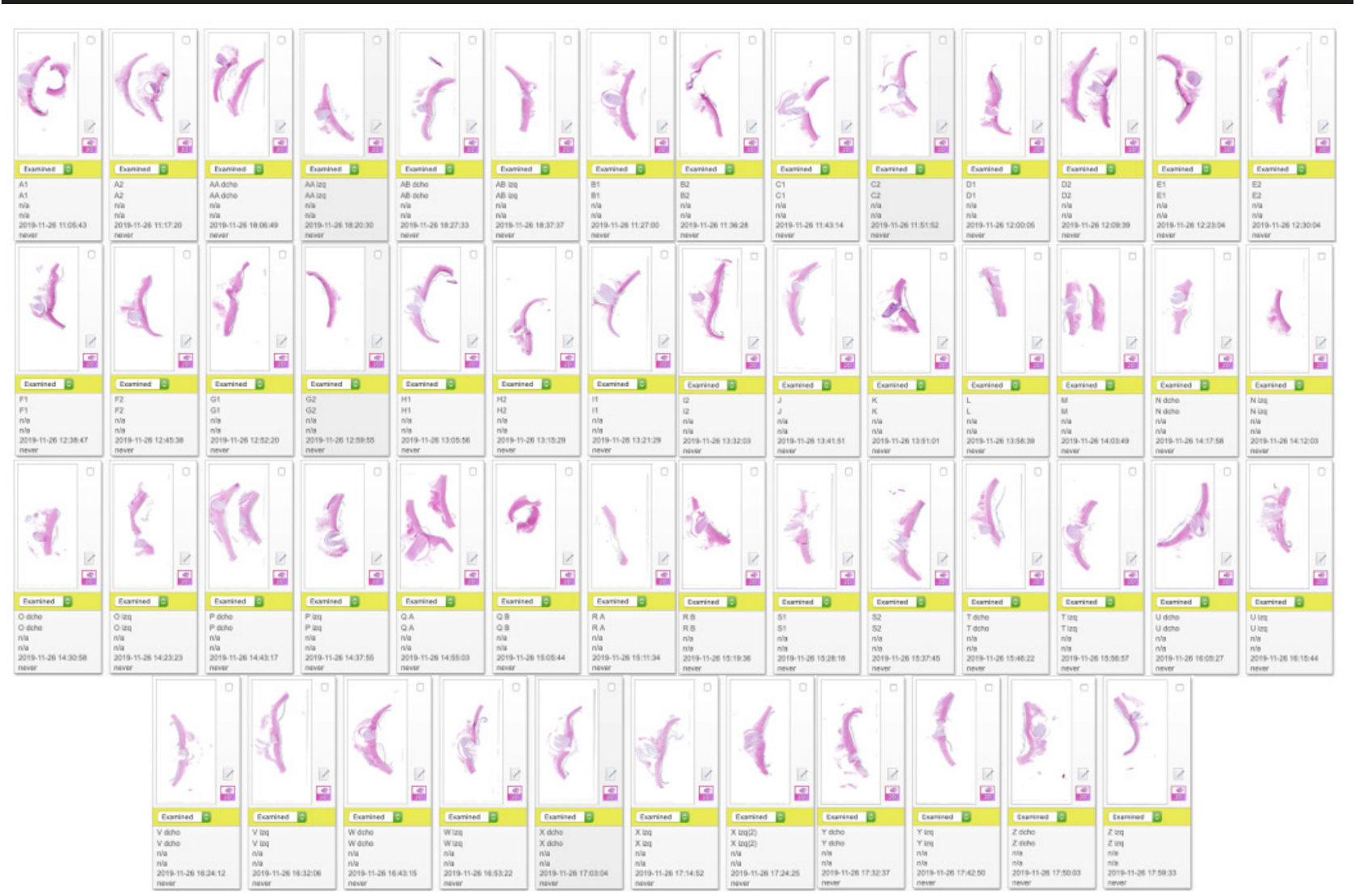

Fig. 21. Cortes histológicos de la retina de los 52 ojos de toro embolado. Fuente: elaboración propia. 


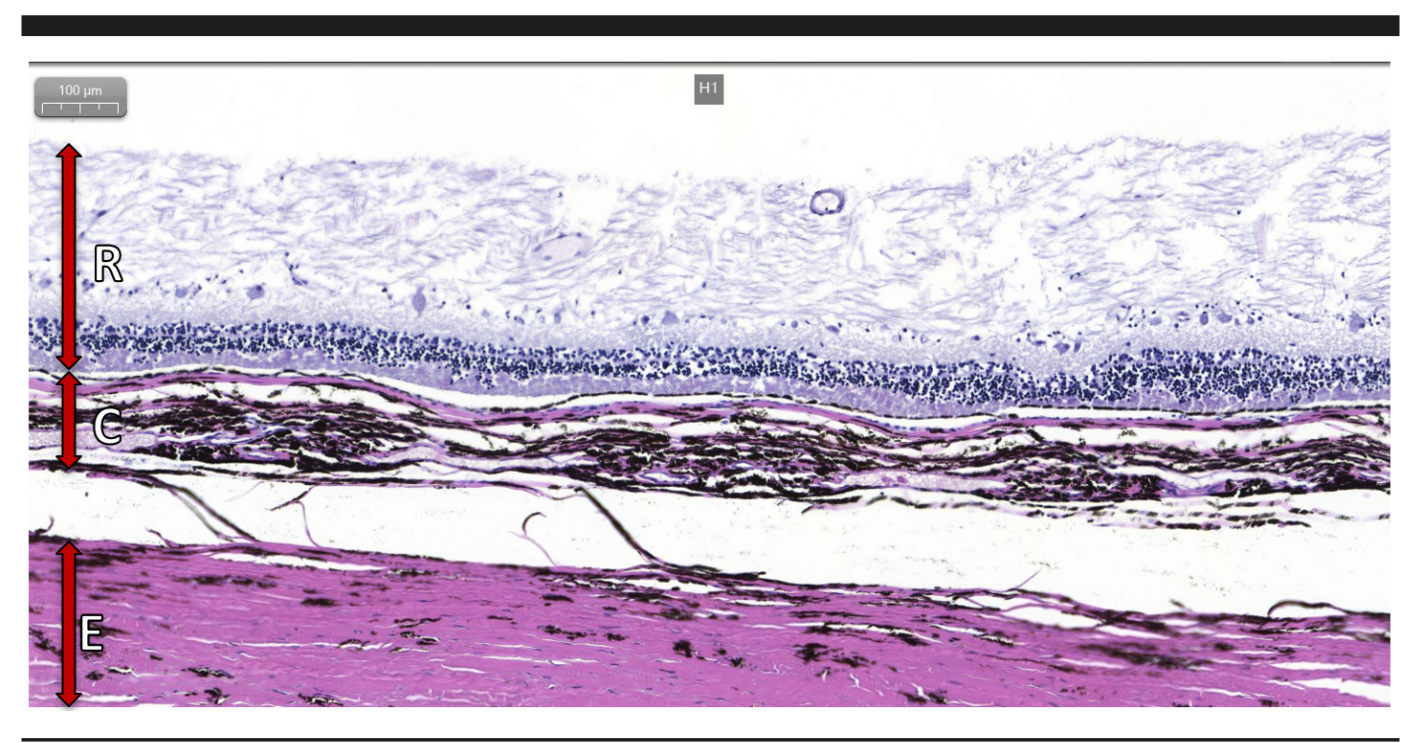

Fig. 22. Corte histológico a 10x de la esclerótica, coroides y retina sin alteración en ninguna de sus capas. E, esclerótica; C, coroides; R, retina. Fuente: elaboración propia.

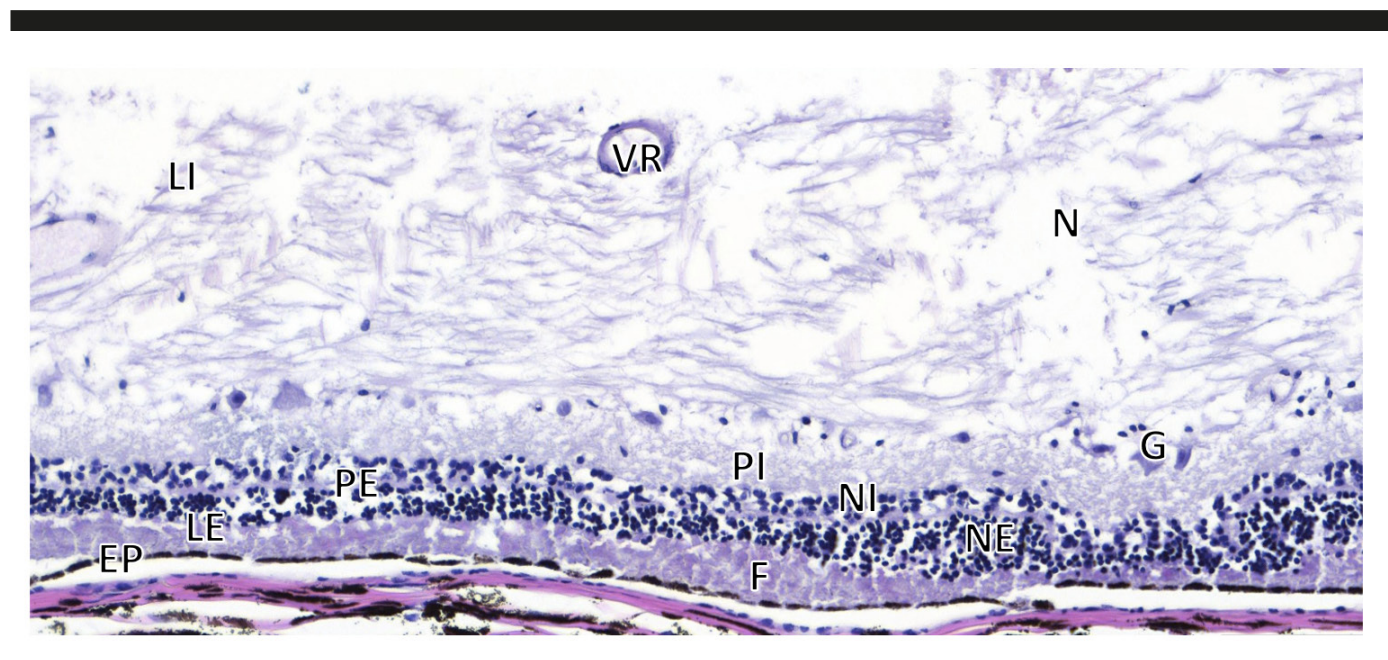

Fig. 23. Corte histológico a 20x de la retina con todas las capas sin alteraciones. EP, epitelio pigmentado; F, capa fotorreceptora; LE, membrana limitante externa; NE, capa nuclear externa; PE, capa plexiforme externa; NI, capa nuclear interna; PI, capa plexiforme interna; G, capa de células ganglionares; N, capa de células nerviosas; LI, membrana limitante interna; VR, vaso retiniano. Fuente: elaboración propia.

A continuación, en las tablas 1 y 2 se muestra la información recopilada de los 52 ojos estudiados. Las muestras se encuentran clasificadas según el código que se les otorgó el día de la recogida y, además, están dividas en ojo derecho y ojo izquierdo. A su vez, se indica el resultado de cada prueba de manera independiente. 
Tabla 1. Resultados

\begin{tabular}{|c|c|c|c|c|c|c|c|c|c|c|}
\hline \multirow[b]{2}{*}{ Muestras } & \multicolumn{5}{|c|}{ OD } & \multicolumn{5}{|c|}{ OI } \\
\hline & $\begin{array}{l}\text { Examen } \\
\text { externo }\end{array}$ & Fluoresceína & Ecografía & Fondo ojo & Histología & $\begin{array}{l}\text { Examen } \\
\text { externo }\end{array}$ & Fluoresceína & Ecografía & Fondo ojo & Histología \\
\hline 181 & $\mathrm{~N}$ & $\mathrm{~N}$ & $\mathrm{~N}$ & M & $\mathrm{N}$ & $\mathrm{N}$ & $\mathrm{N}$ & $\mathrm{N}$ & $\mathrm{X}$ & $\mathrm{N}$ \\
\hline 182 & $\mathrm{~N}$ & $\mathrm{~N}$ & $\mathrm{~N}$ & M & $\mathrm{N}$ & OC & + & $\mathrm{N}$ & M & $\mathrm{N}$ \\
\hline 183 & $\mathrm{~N}$ & $\mathrm{~N}$ & $\mathrm{~N}$ & M & $\mathrm{N}$ & $\mathrm{N}$ & $\mathrm{N}$ & $\mathrm{N}$ & M & $\mathrm{N}$ \\
\hline 184 & $\mathrm{~N}$ & $\mathrm{~N}$ & $\mathrm{~N}$ & $\mathrm{X}$ & $\mathrm{N}$ & $\mathrm{N}$ & $\mathrm{N}$ & $\mathrm{N}$ & M & $\mathrm{N}$ \\
\hline 185 & $\mathrm{~N}$ & $\mathrm{~N}$ & $\mathrm{~N}$ & M & $\mathrm{N}$ & OC & $\mathrm{N}$ & $\mathrm{N}$ & M & $\mathrm{N}$ \\
\hline 186 & $\mathrm{~N}$ & $\mathrm{~N}$ & $\mathrm{~N}$ & M & $\mathrm{N}$ & $\mathrm{N}$ & $\mathrm{N}$ & $\mathrm{N}$ & M & $\mathrm{N}$ \\
\hline 187 & $\mathrm{~N}$ & $\mathrm{~N}$ & $\mathrm{~N}$ & M & $\mathrm{N}$ & $\mathrm{N}$ & $\mathrm{N}$ & $\mathrm{N}$ & $\mathrm{X}$ & $\mathrm{N}$ \\
\hline 188 & $\mathrm{~N}$ & $\mathrm{~N}$ & $\mathrm{~N}$ & M & $\mathrm{N}$ & $\mathrm{N}$ & $\mathrm{N}$ & $\mathrm{N}$ & M & $\mathrm{N}$ \\
\hline 189 & $\mathrm{~N}$ & $\mathrm{~N}$ & $\mathrm{~N}$ & $X$ & $\mathrm{~N}$ & $\mathrm{~N}$ & $\mathrm{~N}$ & $\mathrm{~N}$ & $X$ & $\mathrm{~N}$ \\
\hline 191 & $\mathrm{~N}$ & $\mathrm{~N}$ & $\mathrm{~N}$ & $X$ & $\mathrm{~N}$ & $\mathrm{~N}$ & $\mathrm{~N}$ & $\mathrm{~N}$ & M & $\mathrm{N}$ \\
\hline 192 & $\mathrm{~N}$ & $\mathrm{~N}$ & $\mathrm{~N}$ & M & $\mathrm{N}$ & $\mathrm{N}$ & + & $\mathrm{N}$ & M & $\mathrm{N}$ \\
\hline 231 & $\mathrm{~N}$ & $\mathrm{~N}$ & $\mathrm{~N}$ & M & $\mathrm{N}$ & $\mathrm{N}$ & $\mathrm{N}$ & $\mathrm{N}$ & M & $\mathrm{N}$ \\
\hline 232 & $\mathrm{~N}$ & $\mathrm{~N}$ & $\mathrm{~N}$ & M & $\mathrm{N}$ & $\mathrm{N}$ & $\mathrm{N}$ & $\mathrm{N}$ & $X$ & $\mathrm{~N}$ \\
\hline 233 & $\mathrm{~N}$ & $\mathrm{~N}$ & $\mathrm{~N}$ & M & $\mathrm{N}$ & $\mathrm{N}$ & $\mathrm{N}$ & $\mathrm{N}$ & M & $\mathrm{N}$ \\
\hline 234 & $\mathrm{~N}$ & $\mathrm{~N}$ & $\mathrm{~N}$ & M & $\mathrm{N}$ & $\mathrm{N}$ & $\mathrm{N}$ & $\mathrm{N}$ & M & $\mathrm{N}$ \\
\hline 235 & $\mathrm{~N}$ & $\mathrm{~N}$ & $\mathrm{~N}$ & M & $\mathrm{N}$ & $\mathrm{N}$ & $\mathrm{N}$ & $\mathrm{N}$ & M & $\mathrm{N}$ \\
\hline 236 & $\mathrm{~N}$ & $\mathrm{~N}$ & $\mathrm{~N}$ & $X$ & $\mathrm{~N}$ & $\mathrm{~N}$ & $\mathrm{~N}$ & $\mathrm{~N}$ & $\mathrm{X}$ & $\mathrm{N}$ \\
\hline 251 & $\mathrm{~N}$ & $\mathrm{~N}$ & $\mathrm{~N}$ & M & $\mathrm{N}$ & $\mathrm{N}$ & $\mathrm{N}$ & $\mathrm{N}$ & M & $\mathrm{N}$ \\
\hline 252 & C & $\mathrm{N}$ & $\mathrm{N}$ & M & $\mathrm{N}$ & $\mathrm{N}$ & $\mathrm{N}$ & $\mathrm{N}$ & $X$ & $\mathrm{~N}$ \\
\hline 253 & $\mathrm{~N}$ & $\mathrm{~N}$ & $\mathrm{~N}$ & M & $\mathrm{N}$ & $\mathrm{N}$ & $\mathrm{N}$ & $\mathrm{N}$ & M & $\mathrm{N}$ \\
\hline 254 & $\mathrm{~N}$ & $\mathrm{~N}$ & $\mathrm{~N}$ & M & $\mathrm{N}$ & $\mathrm{N}$ & $\mathrm{N}$ & $\mathrm{N}$ & M & $\mathrm{N}$ \\
\hline 255 & $\mathrm{~N}$ & $\mathrm{~N}$ & $\mathrm{~N}$ & M & $\mathrm{N}$ & C & + & $\mathrm{N}$ & M & $\mathrm{N}$ \\
\hline 256 & $\mathrm{~N}$ & $\mathrm{~N}$ & $\mathrm{~N}$ & M & $\mathrm{N}$ & $\mathrm{N}$ & $\mathrm{N}$ & $\mathrm{N}$ & M & $\mathrm{N}$ \\
\hline 257 & $\mathrm{~N}$ & $\mathrm{~N}$ & $\mathrm{~N}$ & M & $\mathrm{N}$ & $\mathrm{N}$ & $\mathrm{N}$ & $\mathrm{N}$ & M & $\mathrm{N}$ \\
\hline 258 & $\mathrm{~N}$ & $\mathrm{~N}$ & $\mathrm{~N}$ & M & $\mathrm{N}$ & $\mathrm{N}$ & $\mathrm{N}$ & $\mathrm{N}$ & $\mathrm{X}$ & $\mathrm{N}$ \\
\hline 259 & $\mathrm{~N}$ & $\mathrm{~N}$ & $\mathrm{~N}$ & M & $\mathrm{N}$ & $\mathrm{N}$ & $\mathrm{N}$ & $\mathrm{N}$ & M & $\mathrm{N}$ \\
\hline
\end{tabular}

OD: ojo derecho; OI: ojo izquierdo. Examen externo: C, cicatriz; OC, opacidad corneal; N, negativo. Fluoresceína: Grado 1, +; Grado 2, ++; Grado 3, +++; Grado 4, ++++; Grado 5, +++++; N, negativo. Ecografía: P, positivo; N, negativo. Fondo ojo: M, presencia de melanina; $\mathrm{X}$, ausencia de melanina. Histología: $\mathrm{P}$, positivo; N, negativo.

Tabla 2. Resultados de hallazgos en porcentaje

\begin{tabular}{ccc}
\hline & Hallazgos & Porcentaje \\
\hline Examen externo* $^{*}$ & 4 & $7,7 \%$ \\
Fluoresceína & 3 & $5,8 \%$ \\
Ecografía & 0 & $0 \%$ \\
Fondo de ojo** & 42 & $80,8 \%$ \\
Histología & 0 & $0 \%$ \\
\hline
\end{tabular}

*Siendo 4 los ojos que han presentado alteraciones durante el examen externo, de los cuales 2 resultaron positivos a la fluoresceína. Por otro lado, un ojo resultó positivo a la fluoresceína sin presentar ninguna otra alteración. **Presencia de melanina. 
Según puede desprenderse de estos resultados, y tal y como puede observarse en la tabla 3 y la figura 24, solo 5 ojos de los 52 examinados presentaron alteraciones en el presente estudio, lo cual representa un $9,6 \%$ del total.

Tabla 3. Resultados de lesiones en porcentaje

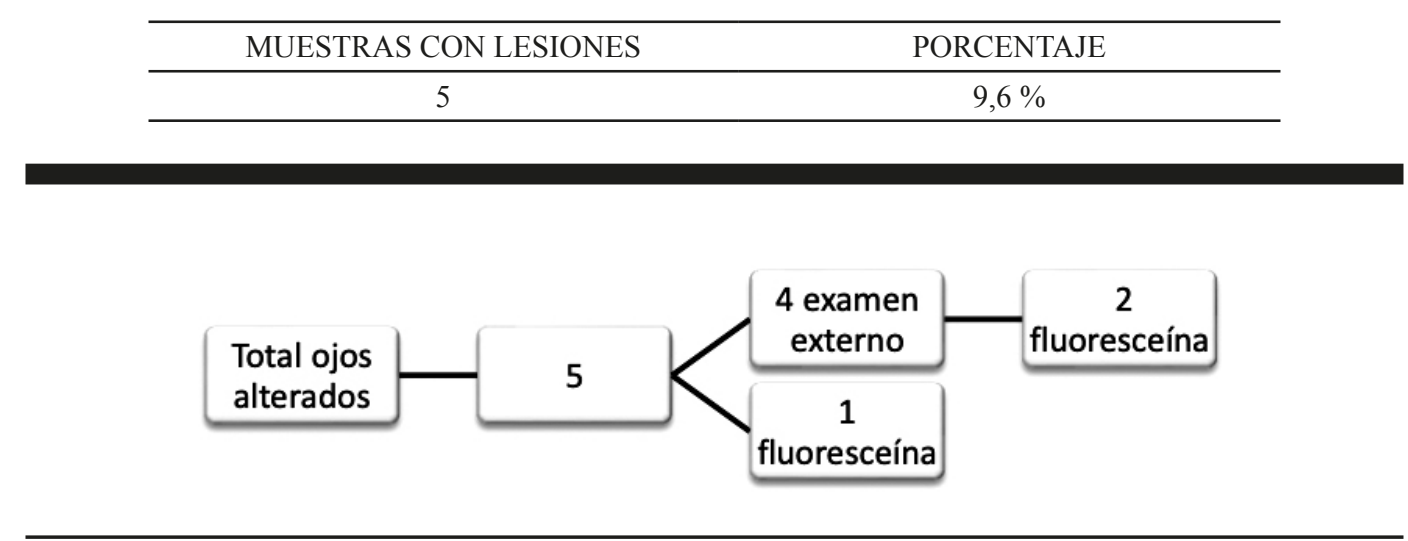

Fig. 24. Total de ojos alterados en el estudio. Fuente: elaboración propia.

\section{DISCUSIÓN}

Según el presente estudio, de las 52 muestras analizadas, tan solo 4 presentaron alteraciones en el examen externo y 2 de estas resultaron positivas a fluoresceína. Solamente 1 muestra resultó positiva a la tinción de fluoresceína sin otra alteración asociada. Por lo tanto, en total fueron 5 los ojos que presentaron diferentes alteraciones.

Respecto a las alteraciones observadas en el examen externo, se trata de lesiones antiguas que el animal pudo sufrir debido a las condiciones de manejo de esta especie.

En relación con las tinciones positivas a fluoresceína, es decir, a las úlceras corneales, al igual que dedujeron Martínez et al. [19], al presentarse en un número de muestras tan pequeño y además al ser las lesiones tipificadas como úlceras tipo 1 , se puede considerar que no están producidas a causa de las bolas de fuego durante el embolado. Algunas de las posibles explicaciones podrían ser que se produzcan a causa del manejo, de las instalaciones de las explotaciones, durante la carga y descarga de los animales en vehículos, y también por peleas de jerarquía en la propia ganadería.

Teniendo como referencia la apariencia normal del ojo de bovino durante el examen ecográfico, según los estudios de Potter et al. [20] en animales vivos y Maghraby et al. [21] en cadáveres, las imágenes obtenidas durante el presente estudio mediante ecografía no mostraron lesiones anatómicas en ninguna muestra. Por lo tanto, como ya indicó el estudio de Ibáñez et al. [22], durante el transcurso de los festejos populares, el animal no desarrolla lesiones oculares, salvo posibles accidentes puntuales.

En cuanto a la presencia de pigmentos de melanina en el fondo del ojo, como también señalan Ibáñez et al. [22] se trata de una característica típica de la especie. 
En el estudio de Khaled Aly [23], se obtuvieron resultados acerca de la apariencia normal de la retina compuesta por 10 capas. Comparándolas con las obtenidas en el presente estudio se corrobora la ausencia de cualquier alteración.

\section{CONCLUSIONES}

Gracias a los resultados obtenidos en el presente trabajo, obtenemos las siguientes conclusiones parciales:

1. Se observan lesiones en el examen externo en el 7,7 \% de las muestras estudiadas.

2. Se evidencian lesiones al test de fluoresceína en el 5,8\% de las muestras analizadas.

3. No se observa ningún tipo de alteración al realizar el examen ecográfico.

4. No aparecen lesiones a nivel del fondo del ojo.

5. A nivel histológico, no se aprecian alteraciones en la retina.

Por tanto, como conclusión se puede indicar que no existe relación entre la presencia de lesiones en los ojos de toros embolados y el proceso de embolado.

\section{REFERENCIAS BIBLIOGRÁFICAS}

[1] Lomillos JM, Alonso ME, Sánchez-García C, Gaudioso V. Evolución del sector de la producción del toro de lidia en España. Censos y ganaderías. ITEA. 2012; 108(2):207-21.

[2] Desarrollo filogenético e histórico. En: ediciones Alimara, editores. El Toro de Lidia. Madrid: Alimara; 1966, pp. 25-47.

[3] Ganado Bovino de Lidia. Federación Española de Asociaciones de Ganado Selecto (FEAGAS) [consultado: 16 marzo 2020]. Disponible en: https://feagas.com/razas/bovino/lidia/

[4] REAL DECRETO 2129/2008, del 26 de diciembre, por el que se establece el Programa nacional de conservación, mejora y fomento de las razas ganaderas. Boletín Oficial del Estado, n. ${ }^{\circ} 23$, $(27 / 01 / 2009)$.

[5] Mazón Marín J. Bou de carrer de la Comunidad Valenciana. Caracterización etnológica y de comportamiento. Economía de su producción [Tesis doctoral]. Zaragoza: Universidad de Zaragoza; 2017.

[6] Liebich HG, König HE. Órgano de la visión. En: Liebich HG, König HE. Anatomía de los animales domésticos. 2. ${ }^{\text {a }}$ ed. Madrid: Panamericana; 2011, pp. 287-305.

[7] Samuelson DA. Ophthalmic Anatomy. En: Gelatt KN, Gilger BC, Kern TJ. 5. ${ }^{\text {a }}$ ed. Veterinary ophthalmology. New Jersey: Wiley- Blackwell; 2013, pp. 39-170.

[8] Rojo Salvador C, González Martínez E. Anatomía del ojo (globo del ojo y órganos accesorios) en las especies domésticas. Reduca. 2013; 5(2):1-15.

[9] Lo Sapio M. Estudio sobre diferentes aspectos de la visión y la anatomía ocular del toro de lidia [Tesis doctoral]. Murcia: Universidad de Murcia; 2015. 
[10] Ofri R. Development and congenital abnormalities. En: Maggs DJ, Miller PE, Ofri R. Slatter's Fundamentals of Veterinary Ophthalmology. 4. ${ }^{a}$ ed. Philadelphia: Saunders; 2007, pp. 20-32.

[11] Hernández Guerra AM, López Murcia M. Oftalmología bovina. Axón Comunicación. 2009;24:38-43.

[12] Aughery E, Frye FL. Special senses (eye). En: Aughery E, Frye FL, editores. Comparative veterinary histology with clinical correlates. London: Manson Publishing; 2001, pp. 227-36.

[13] La óptica del cristalino del bovino como posible modelo de presbicia [Tesis doctoral]. Murcia: Universidad de Murcia; 2020.

[14] Hugues B, Navaroli F, Torres M, Soto CJ. La visión cromática en los animales (Chromatic vision in animals). Redvet. 2008;9(11):1-6.

[15] Bacha WJ, Bacha LM. The eye. En: Bacha WJ, Bacha LM, editores. Color atlas veterinary his-

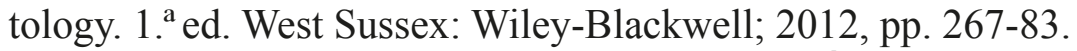

[16] De la Cruz J, Dauria P, Castagnino R, Ibáñez N. Órganos de los sentidos: ojo. En: De la Cruz J, Dauria P, Castagnino R, Ibáñez N, editores. Manual práctico de histología veterinaria. Córdoba (Argentina): Universidad de Río Cuarto; 1999, pp. 149-54.

[17] Pizzirani S, Penninck D, Spaulding K. Eye and Orbit. En: Penninck D, d'Anjou M, editores. Atlas of small animal ultrasonography. 2. ${ }^{\text {a }}$ ed. West Sussex: Wiley-Blackwell; 2015, pp. 19-55.

[18] Fluoresceína. Vademecum. Madrid: Vidal Vademecum Spain; 2017 [consultado: 2 abril 2020]. Disponible en: https://www.vademecum.es/principios-activos-fluoresceina-s01ja01

[19] Martínez-Ros P, López-Murcia MM, Jiménez Trigos E, Ortega Poncel J, Mayordomo Febrer A, Gómez Martín A, et al. Descripción de hallazgos oculares en toros embolados de la comunidad valenciana. Estudio preliminar. En: IX Congreso Mundial Taurino de Veterinaria. 2017 Jun 2224; Toledo. Madrid: Consejo General de Colegios Veterinarios de España; 2017, pp. 121-7.

[20] Potter TJ, Hallowell GD, Bowen M. Ultrasonographic Anatomy of the Bovine Eye. Vet Radiol Ultrasound. 2008;49(2):172-5.

[21] El-Maghraby HM, Nyland TG, Bellhorn RW. Ultrasonographic and biometric evaluation of sheep and cattle eyes. Vet Radiol Ultrasound. 1995;36(2):148-51.

[22] Ibáñez Sanchis C, Ferreres Fuster D, Mazón Marín J. Estudio preliminar sobre la existencia de lesiones oculares tras la lidia o el embolado de los toros. Nereis. 2019;11:81-103.

[23] Aly K. Glycohistochemical, immunohistochemical and Electron Microscopic Examination of the Bovine Eyeball [Tesis doctoral]. Munich: Universidad de Munich; 2003. 